\title{
Brasil: efectos del COVID-19 y recuperación ${ }^{1}$
}

\author{
Luiz Carlos Bresser-Pereira
}

\section{Resumen}

En este artículo se examinan los efectos de la enfermedad por coronavirus (COVID-19) en la población y la economía del Brasil, su elevada mortalidad por cada 100.000 habitantes y su lenta estabilización. Se hace una breve comparación con lo que ocurre en un país similar de América Latina, la Argentina, donde los resultados en términos de mortalidad por cada 100.000 habitantes fueron mejores, y en Francia, donde la recuperación fue más marcada. También se evalúa la eficiencia en los gastos y se observa que la comparación tampoco es favorable para el Brasil. Por último, se aborda el problema del financiamiento y se argumenta que solo la Argentina recurrió a la compra de bonos del tesoro por el banco central del país, la política adoptada en la mayoría de los países ricos que tienen una moneda y un banco central propios (no es el caso de Francia).

\section{Palabras clave}

COVID-19, virus, epidemias, aspectos económicos, aspectos demográficos, mortalidad, salud, política económica, política sanitaria, gastos públicos, financiación, Brasil

\section{Clasificación JEL}

118, O29, E5

\section{Autor}

Luiz Carlos Bresser-Pereira es Profesor Emérito de la Fundación Getulio Vargas. Correo electrónico: luiz.bresser@fgv.br; sitio web: www.bresserpereira.org.br. 


\section{Introducción}

Entre las décadas de 1930 y 1980, el Brasil creció de manera satisfactoria y se industrializó en el marco de un régimen de política económica desarrollista. En los años setenta cometió el error de endeudarse y en la década siguiente se vio afectado por la gran crisis de la deuda externa, a la que se sumó una elevada inflación inercial. Debilitado por la crisis y bajo la presión del Norte, que en 1980 había virado hacia el liberalismo económico, entre 1990 y 1992 el Brasil implementó una apertura comercial y financiera, entró en un proceso de desindustrialización prematura y volvió a ser un mero exportador de productos básicos. Desde entonces, experimenta un proceso de cuasiestancamiento que solo se interrumpió durante un período, en la década de 2000, debido al auge de los productos básicos. Entre 1950 y 1980, en el marco de un nacionalismo desarrollista, el ingreso per cápita creció a una elevada tasa del 3,5\% anual. Desde 1980 este indicador crece un 0,8\% al año, en comparación con el 1,5\% anual en los países ricos y el 3,0\% anual en los países en desarrollo en ese mismo período. En 2014 el país entró en una profunda recesión, seguida de una recuperación muy insatisfactoria que confirmó el cuadro general de cuasiestancamiento.

Fue en ese marco económico que el Brasil, como todos los demás Estados nación, se enfrentó a la pandemia de enfermedad por coronavirus (COVID-19) a comienzos de 2020. Algunos países lo hicieron mejor que otros, en términos de número de muertes, desempleo, aumento de la pobreza, reducción del producto interno bruto (PIB) y endeudamiento público. Si bien es difícil clasificar a los países según su éxito o fracaso en estos cinco criterios, es posible afirmar con cierta seguridad que los resultados del Brasil y los Estados Unidos fueron peores que los de China y Nueva Zelandia. Por otra parte, sabemos que los resultados obtenidos fueron mejores cuanto más rápido se enfrentó el problema en cada país, cuanto más eficaces fueron las medidas de aislamiento o distanciamiento físico, cuantas más pruebas se realizaron y cuanto más cuidadosos fueron el seguimiento de los infectados y el rastreo de sus contactos, cuanto más fuerte y correcta fue la orientación del gobierno a la población con respecto a esas medidas, cuanto más solidarios fueron los habitantes de cada país ante la pandemia y cooperaron con el gobierno en la adopción de conductas orientadas a disminuir la propagación de la enfermedad, cuanto mejor era ya el sistema de salud pública, cuanto más apoyo presupuestario tuvo este cuando estalló la pandemia, cuanto más y mejor gastó el Estado para disminuir el número de muertes, limitar el aumento del desempleo y la quiebra de las empresas y la reducción de la demanda, y, por último, según la forma en que se financiaron los gastos de emergencia, ya sea mediante el endeudamiento del Estado con el sector privado y el aumento de la deuda pública o mediante el financiamiento monetario (la compra por el banco central de bonos emitidos por el tesoro para los gastos relacionados con la pandemia).

En este ensayo abordaré el caso del Brasil y examinaré sus malos resultados en la gestión de la pandemia. ¿Hay alguna relación entre el bajo crecimiento de la economía brasileña desde 1980 y el elevadísimo número de muertes a causa del COVID-19? Aunque no es posible afirmar con certeza que esa relación exista, de una cosa estoy seguro: para que un Estado nación pueda desarrollarse y enfrentar los nuevos problemas que surgen continuamente la nación debe estar unida. Ahora bien, la cohesión de la nación brasileña, que había aumentado en gran medida en los años ochenta con la construcción de una coalición de clases popular-democrática y la aprobación de una constitución social y desarrollista, no logró que el país reanudara el crecimiento interrumpido en 1980. Con las grandes manifestaciones populares de junio de 2013 quedó claro que esa unión era una cosa del pasado. Para evaluar si el Brasil realmente fracasó al enfrentar el COVID-19, en este artículo haré una breve comparación con la Argentina y Francia. 


\section{Políticas públicas}

Las políticas públicas adoptadas por los países para hacer frente a la pandemia fueron de tres tipos: i) sanitarias, destinadas a disminuir el número de personas infectadas y el número de muertes; ii) fiscales, destinadas a garantizar un ingreso mínimo a la población, reducir el desempleo, la quiebra de las empresas y la caída del PIB causados por las medidas sanitarias, y iii) financieras, destinadas a financiar los gastos relacionados con el COVID-19.

Entre las políticas sanitarias que recomendaron los infectólogos y las instituciones sanitarias internacionales y que resultaron eficaces se incluyen: el cierre de las fronteras del país, la prohibición del ingreso de vuelos internacionales, el cierre de las ciudades o regiones afectadas, la realización de pruebas masivas, el rastreo y aislamiento de los contactos de las personas con pruebas positivas, el uso obligatorio de mascarillas, la implementación de hospitales o camas de emergencia, la provisión de respiradores suficientes, la gratuidad de las pruebas y del tratamiento de salud, la orientación de la población sobre las conductas individuales y la prohibición o la estricta restricción de los despidos. Estas son las medidas que se tomaron en dos países que lograron enfrentar la pandemia con gran éxito: un país muy grande, China, y un país muy pequeño, Nueva Zelandia.

La política fiscal adecuada consistió en aumentar considerablemente el gasto público, dejando de lado la preocupación por el fuerte incremento del déficit público. Se trataba de ampliar el gasto público en: i) el área de la salud, aumentando el número de camas en los hospitales y la disponibilidad de los equipos y medicamentos indicados para tratar la enfermedad; ii) la ampliación de la asistencia en caso de desempleo; iii) una política de ingresos básicos para los más pobres; iv) una política de estímulo a las empresas para que no despidieran empleados, y v) diversas políticas de apoyo a las empresas para evitar su quiebra. En términos más generales, se trataba de adoptar una política anticíclica de expansión de la inversión pública. Estas fueron las políticas adoptadas en los países que enfrentaron la pandemia de manera más competente en el ámbito económico.

\section{Criterios y políticas}

Para esta comparación escogí dos países: la Argentina, por ser un país de ingresos medios como el Brasil que, no obstante los graves problemas que enfrenta, logró evitar un gran número de muertes, y Francia, porque me pareció interesante incluir un país rico en la comparación. Como criterios de éxito o fracaso en el enfrentamiento del COVID-19 elegí un número limitado de indicadores: el número de muertes por cada 100.000 habitantes, el aumento de la tasa de desempleo, el incremento de la pobreza o la desigualdad, la tasa de disminución del PIB y el valor del gasto realizado más la pérdida de ingresos del Estado. Los datos obtenidos se presentan en el cuadro 1. Si bien no son completamente comparables, dan una buena idea del desempeño de cada país. 
Cuadro 1

El COVID-19 en el Brasil, la Argentina y Francia

\begin{tabular}{lccc}
\hline & Brasil & Argentina & Francia \\
\hline Muertes por cada 100000 habitantes $^{\mathrm{a}}$ & 52,3 & 14,2 & 46,5 \\
\hline Aumento de la tasa de desempleo (en puntos porcentuales) & 2,3 & $1,5^{\mathrm{b}}$ & $-0,5$ \\
\hline Aumento de la pobreza o la desigualdad & $-0,9 \%$ & $11,5 \%$ & $0,0 \%$ \\
\hline Tasa de disminución del producto interno bruto (PIB) & $-9,1 \%$ & $-9,9 \%$ & $-12,5 \%$ \\
\hline Gasto más pérdida de ingreso (como porcentaje del PIB) & $11,8 \%^{\mathrm{c}}$ & $6,7 \%$ & $6,9 \%$ \\
\hline
\end{tabular}

Fuente: Elaboración propia, sobre la base de Organización Mundial de la Salud (OMS), "WHO Coronavirus Disease (COVID-19) Dashboard", 2020 [base de datos en línea] https://covid19.who.int/; Worldometers.info, "World Population", 2020 [base de datos en línea] https://www.worldometers.info/es/; Institución Fiscal Independiente, Relatório de Acompanhamento Fiscal, № 43, 17 de agosto de 2020 [en línea] https://www2.senado.leg.br/bdsf/bitstream/handle/ id/575506/RAF43_AGO2020.pdf; Instituto Nacional de Estadística y Censos (INDEC), "Mercado de trabajo: tasas e indicadores socioeconómicos (EPH)”, Trabajo e Ingresos, vol. 4, № 3, junio de 2020; Organización de Cooperación y Desarrollo Económicos (OCDE), "Unemployment rate", 2020 [base de datos en línea] https://data.oecd.org/unemp/ unemployment-rate.htm; J. Cuaresma y otros, "Poverty headcount ratio at \$3.20/day", 2019 [base de datos en línea] https://dashboards.sdgindex.org/explorer/sdg1_320pov; Fondo Monetario Internacional (FMI), "Actualización de las perspectivas de la economía mundial", 2020a [en línea] https://www.imf.org/es/Publications/WEO/Issues/2020/06/24/ WEOUpdateJune2020; FMI, "Policy responses to Covid-19", 2020b [en línea] https://www.imf.org/en/Topics/imf-andcovid19/Policy-Responses-to-COVID-19.

Nota: A menos que se indique otra cosa, los datos corresponden a los dos primeros trimestres de 2020.

a Tras un mismo número de días para los tres países (151 días desde la primera muerte).

b Variación de la tasa de desempleo entre el cuarto trimestre de 2019 y el primer trimestre de 2020.

c Según la Institución Fiscal Independiente (2020), la ejecución por el Gobierno federal de los gastos y créditos liberados fue del $50,6 \%$

\section{Número de muertes por cada 100.000 habitantes}

El resultado más importante es, sin duda, el número de muertes por cada 100.000 habitantes. De acuerdo con las estadísticas oficiales utilizadas, el número de muertes en el Brasil fue mayor que en Francia y mucho mayor que en la Argentina. Sin embargo, este número está definitivamente subestimado. Paulo Lotufo, epidemiólogo de la Universidad de São Paulo, afirmó que las muertes se están subestimando en todos los países. Por ejemplo, según The New England Journal of Medicine, el número de muertes causadas por el COVID-19 en Italia fue un 30\% mayor que la cifra estimada, mientras en São Paulo, el estado más poblado y rico del Brasil, ese número sería un 170\% mayor (Ruprecht, 2020). De acuerdo con cálculos del Imperial College London realizados en junio de 2020, las muertes por el coronavirus serían el triple de las que constan en las estadísticas (Sousa Pinto, 2020).

El número de muertes por COVID-19 fue ciertamente menor cuanto más firmes fueron los gobiernos al establecer las medidas de confinamiento y cuarentena, cuanto mayor fue el número de pruebas realizadas y cuanto mejores fueron el seguimiento de los infectados, el rastreo de sus contactos y la asistencia médica y hospitalaria. Además, el tiempo entre el primer caso de contagio verificado en el país y el inicio de la política de contención de la enfermedad también fue una variable crucial. Cuanto menor fue el número de días entre los dos hechos, menor fue la propagación inicial de la enfermedad y menor, naturalmente, el número de personas infectadas. El número de muertes en la Argentina fue mucho menor que en Francia porque el Gobierno argentino reaccionó con mayor rapidez que el francés. Según Natanson (2020), pese a las preocupaciones expresadas por los gobernadores de las provincias y los alcaldes con respecto a las consecuencias sociales de un cierre riguroso y firme, el Presidente Alberto Fernández actuó con celeridad y eligió el camino aparentemente menos popular de adoptar un estricto sistema de aislamiento y cuarentena. En Francia, como en los principales países de Europa, hubo un retraso mayor, que puede explicarse por el hecho de que fueron afectados por el coronavirus antes que el Brasil y la Argentina. Sin embargo, una vez que el Gobierno francés tomó las medidas necesarias, lo hizo de manera competente y el número de muertes disminuyó. El caso del Brasil fue 
muy diferente. De acuerdo con el epidemiólogo citado, Paulo Lotufo, el Brasil podría haber tenido un tercio de las muertes y la mitad de los casos del nuevo coronavirus si el distanciamiento se hubiera adoptado de manera más eficaz desde el principio (UOL, 2020).

En el gráfico 1 se muestra el número de muertes diarias causadas por el COVID-19 en los 151 días desde el primer caso de muerte en cada país. Se eligió el período de 151 días porque, a la fecha de redacción de este artículo, era el tiempo que había transcurrido desde el comienzo de la pandemia en la Argentina (el último de los tres países en resultar afectado por la enfermedad). En el gráfico se observa que el mejor desempeño corresponde a la Argentina. En este caso, la rapidez de actuación del Gobierno fue crucial. Como en muchos países en los que el COVID-19 se manifestó de manera temprana, las autoridades francesas tardaron en actuar y la enfermedad se propagó, pero luego actuaron con firmeza al adoptar las políticas necesarias y el número de muertes disminuyó considerablemente. El Brasil fracasó por completo y el número de muertes creció hasta alcanzar un valor máximo 75 días después de la primera muerte, pues, a diferencia de lo que ocurrió en Francia, el Gobierno no fue capaz de adoptar políticas para reducir la curva de contagios.

Gráfico 1

Argentina, Brasil y Francia: muertes diarias por cada millón de habitantes desde la primera muerte por COVID-19, 2020

(En número de personas)

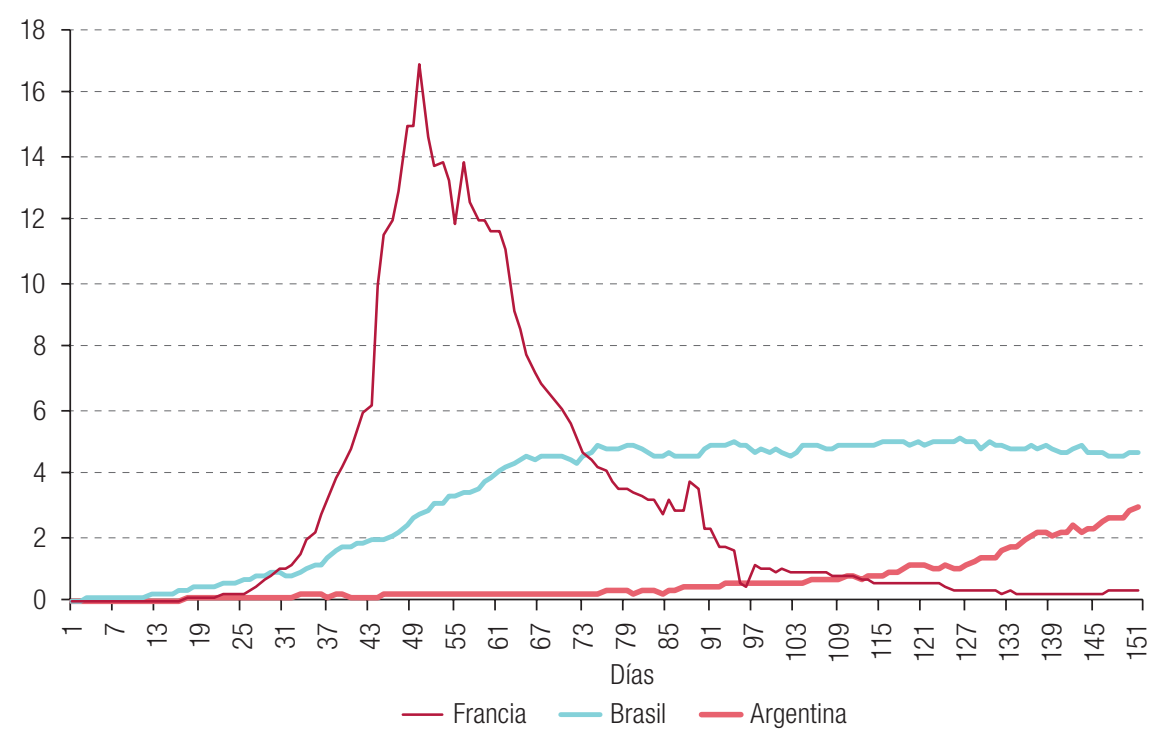

Fuente: Organización Mundial de la Salud (OMS), "WHO Coronavirus Disease (COVID-19) Dashboard”, 2020 [base de datos en línea] https://covid19.who.int/.

Nota: Media móvil de siete días desde el primer caso de muerte.

No se puede decir que el Gobierno federal, que era el principal responsable de la política que se debía aplicar, tardara en tomar medidas para combatir el virus, porque en realidad no hizo prácticamente nada excepto dificultar la actuación del Sistema Único de Salud (SUS) brasileño, los gobernadores y los alcaldes. De hecho no hubo una política de contención de la pandemia hasta que los funcionarios públicos asociados al SUS, los gobernadores de los estados y los alcaldes decidieron iniciar la política de confinamiento por su cuenta, a pesar de las críticas del Presidente, que no dejaba de decir que el problema no era grave, que no tenía sentido detener las empresas y las escuelas y que bastaba con suministrar a los hospitales y clínicas públicas de consulta externa dos medicamentos utilizados para la malaria (cloroquina e hidroxicloroquina), cuya eficacia contra el COVID-19 no se ha demostrado hasta ahora y que presentan importantes contraindicaciones. Los estudios realizados hasta la fecha 
muestran que estos medicamentos no funcionan ni siquiera cuando se suministran en la fase inicial de la enfermedad, como comenzó a recomendar el Ministerio de Salud por indicación del Presidente. En un escenario dramático como el de la pandemia, el país ya ha cambiado de Ministro de Salud tres veces y, mientras escribo este artículo (a principios de septiembre), dirige el Ministerio de manera interina el general Eduardo Pazuello, que no es médico ni ha tenido en su carrera ninguna relación cercana con las políticas de salud. Los gobernadores y los alcaldes, por otra parte, actuaron de manera básicamente correcta, pero sin el apoyo que necesitaban del Gobierno federal. Al comienzo de la pandemia hubo un conflicto abierto entre el Presidente y los principales gobernadores, pero después de menos de dos meses algunos de ellos - en particular el de São Paulo, que estaba implementando una política de confinamiento adecuada - sufrieron la presión de los empresarios del comercio y los restaurantes y flexibilizaron la política.

\section{Costo de las políticas sanitarias y la protección económica}

¿Cuánto gastaron los tres países analizados en hacer frente al coronavirus, reducir el número de muertes, evitar el hambre entre los más pobres, limitar el aumento del desempleo y reducir la quiebra de empresas? ¿Y cuánto disminuyeron sus ingresos fiscales debido a las políticas de confinamiento y cuarentena? ¿A cuánto asciende la inversión de los países para mitigar los efectos del COVID-19, si se suma el aumento de los gastos y la disminución de los ingresos? En el cuadro 1 se observa que, sorprendentemente, el gasto fue mayor en el Brasil, donde el Gobierno federal no tuvo una política de contención de la enfermedad y de apoyo a las personas y a las empresas, pues llegó al 11,8\% del PIB, en comparación con el 6,7\% en la Argentina y el 6,9\% en Francia. La explicación es sencilla: un mes después del comienzo de la pandemia, el Gobierno propuso una ayuda de emergencia mensual de 200 reales, a partir de abril, para los trabajadores informales, los microempresarios individuales, los trabajadores por cuenta propia y los desempleados. Sin embargo, el Congreso Nacional rechazó la propuesta y la multiplicó por tres, sin que estuviera claro - tanto para el Ministerio de Economía como para el Congreso Nacional - cuántos serían los beneficiarios de la medida, que fueron aproximadamente 60 millones de personas. La prestación se mantuvo en ese valor desde abril hasta agosto y se redujo a la mitad para el período de septiembre a diciembre. En diciembre el gasto total debería ser de 450.000 millones de reales, que representan cerca del $7 \%$ del PIB.

¿Cuán eficiente fue ese gasto? Si bien no es posible presentar una única medida de eficiencia para cada país, porque los resultados no solo se relacionan con la reducción del PIB, sino también con el número de muertes, el aumento del desempleo y el incremento de la desigualdad, no es difícil concluir que el gasto en el Brasil fue sumamente ineficiente. Aunque fue el país que más gastó, fue también aquel donde se registraron el mayor número de muertes por cada 100.000 habitantes y el mayor aumento del desempleo. Naturalmente, presentó un mejor desempeño en relación con la pobreza, pero esto se explica por la dimensión de la ayuda de emergencia no prevista por el Gobierno.

\section{El problema del financiamiento}

¿Cómo se financiarán los elevados gastos relacionados con el COVID-19? Al contrario de lo que sucede en la mayoría de los países ricos que disponen de una moneda y un banco central propios (The Economist, 2020) y de lo que se hizo en la Argentina ${ }^{2}$, donde se está financiando una parte nunca

2 La Argentina se financió a partir de utilidades recibidas del Banco Central. Véase OPC (2020, pág. 5). 
declarada pero elevada de esos gastos mediante la emisión de dinero, los otros dos países analizados recurrieron a un financiamiento ortodoxo mediante el aumento de la deuda con el sector privado. A mi juicio, este es un error que el Brasil podría haber evitado. Con el estallido de la pandemia, se aprobó en el Congreso Nacional brasileño la Enmienda Constitucional 106 (denominada "Presupuesto de Guerra"), que instituyó un régimen fiscal, financiero y de contratación extraordinario para atender las necesidades derivadas del estado de calamidad pública. Este autorizó la flexibilización de la Ley de Responsabilidad Fiscal (Ley Complementaria 101/2000) y el incumplimiento de la "regla de oro" en materia presupuestaria, que determina que los ingresos procedentes de las operaciones de crédito no pueden utilizarse para financiar gastos corrientes. En la propuesta de enmienda se incluía el permiso, concedido excepcionalmente al Banco Central del Brasil, para comprar nuevos títulos de la Secretaría del Tesoro Nacional destinados a financiar los gastos relacionados con el COVID-19, pero esta no tuvo el apoyo del Gobierno y fue rechazada por los miembros del Congreso Nacional. A mi juicio, esto fue un error; los gobiernos que no adoptaron la emisión de dinero para financiarse perdieron autonomía sobre el monto del gasto en relación con el COVID-19, mientras el financiamiento con el sector privado supuso un aumento de la deuda pública.

Una variable explicativa importante para la definición del valor de los gastos de cada país en relación con el COVID-19 fue, probablemente, la forma de financiamiento elegida (venta de bonos emitidos por el tesoro al sector privado o al banco central). Los países que adoptaron el financiamiento monetario se sintieron libres de gastar más, porque, pese a que esa decisión podía conllevar un déficit público elevado, la deuda pública neta (entendida como la deuda del tesoro menos sus deudas con el banco central) se habría mantenido constante.

Hasta la crisis financiera mundial de 2008 existía un veto a la política de emisión de dinero por los bancos centrales, compartido incluso por los economistas que, por una parte, consideraban la oferta de dinero como endógena, y, por otra, negaban la tesis monetarista de que el aumento de la oferta de dinero sería la causa de la aceleración de la inflación. Sin embargo, después de esa crisis, los bancos centrales de los países ricos pusieron en práctica la "flexibilización cuantitativa", que suponía la compra de títulos del sector privado y de nuevos bonos emitidos por el tesoro, configurándose, en este segundo caso, el financiamiento monetario. Los objetivos eran aumentar la oferta de dinero o la liquidez del sistema económico, reducir las tasas de interés y, de ese modo, incentivar a las empresas a invertir o a los consumidores a consumir. El aumento de las inversiones y del consumo no se produjo, y las economías de los países ricos se mantienen casi estancadas desde 2008. Sin embargo, hubo una consecuencia probablemente involuntaria (excepto, a mi juicio, en el caso del Japón), que consiste en la gran disminución de la deuda pública de los países que emitieron dinero oficialmente. La reducción de la deuda pública de los Estados Unidos fue relativamente pequeña, cerca del 12\%, y ese puede ser el motivo por el cual los economistas estadounidenses no le prestaron mucha atención. En el caso del Japón, cuya deuda era enorme, el aumento de la oferta de dinero mediante la flexibilización cuantitativa fue igualmente enorme y redujo esa deuda un $77 \%$. El objetivo de la medida no era reducir la deuda pública, pero en el caso del Japón la flexibilización cuantitativa fue tan grande que es difícil creer que el Gobierno japonés no considerara también ese hecho al ponerla en práctica. El financiamiento monetario no implica, objetivamente, el aumento de la deuda pública, pero no es eso lo que dice la contabilidad pública "oficial". El hecho de que el tesoro y el banco central formen parte del mismo aparato estatal no se tuvo en cuenta, porque las reglas internacionales de contabilidad pública no lo permiten. Como puede apreciarse, no solo a los economistas, sino también a los contadores públicos les gusta la ficción, una ficción que, en este caso, desalentaría los gastos públicos "irresponsables", incluso aunque estos no causaran inflación.

La emisión de dinero no causa inflación, incluso aunque creyéramos en la teoría cuantitativa del dinero, porque la cantidad de dinero en circulación en una economía es endógena. Esta no depende de la cantidad de dinero emitida por el Estado, sino de cuánto gasten el Estado, las empresas y las 
familias y de cuánto se financien para realizar ese gasto. En el caso de los gastos relacionados con el COVID-19, hay dos formas de financiarlos: el tesoro vende sus títulos de deuda al sector privado o bien al banco central. En las dos hipótesis, el aumento de la cantidad de dinero es el mismo. Si el gasto financiado de una u otra forma no causa un aumento de la demanda superior a la oferta agregada, esta no causa una aceleración de la inflación. Esto fue lo que ocurrió con la flexibilización cuantitativa y es lo que ocurre ahora con el COVID-19. En este caso hay un aumento del gasto público, pero este apenas compensa parcialmente la disminución de las inversiones y el consumo del sector privado causada por la pandemia.

Por otro lado, la oferta de dinero es endógena: el aumento de la cantidad de dinero ocurre de todos modos cuando hay un aumento del gasto, independientemente de la forma en que es financiado, y el aumento de la cantidad de dinero no causa inflación si no lleva al país al área del pleno empleo. Sin embargo, existe un antiguo temor entre las personas a que el financiamiento monetario del Estado cause inflación, que probablemente se originó hace mucho tiempo, cuando "inflación" no significaba "aumento de precios" sino "aumento descontrolado de la cantidad de dinero en la economía"3. Este mito fue resucitado por el monetarismo. El argumento básico del monetarismo era que, si los bancos centrales controlaban firmemente la oferta de dinero, se controlaría la inflación. En la literatura económica existe una identidad, la ecuación de intercambio (MV = Yp), en la que $M$ es la cantidad de dinero, $V$ es la velocidad de la moneda o el número de veces que una unidad monetaria circula en un año, Y es el ingreso nacional y p la inflación. Es una identidad porque parte de la definición de la velocidad de circulación del dinero $(V=$ Yp / M).

No obstante, los monetaristas transformaron esa identidad en una teoría (la teoría cuantitativa), asumiendo que la velocidad de la moneda es constante y afirmando que el aumento de $\mathrm{M}$ causa el aumento de la inflación, p. Aparentemente, esta teoría es cierta porque existe una estrecha correlación entre la cantidad de dinero y la inflación, pero, en primer lugar, $V$ no es constante, la velocidad de la moneda es extremadamente variable y cambia con el ciclo económico ${ }^{4}$. En segundo lugar, no hay razón para decir que el aumento de $\mathrm{M}$ es la causa del aumento de $\mathrm{p}$. Tiene más sentido decir que es el aumento de la inflación el que requiere que la oferta de dinero nominal aumente en la medida en que la cantidad de dinero existente en una economía es endógena (está determinada por la dinámica del propio sistema económico). Una economía nacional necesita un nivel de liquidez o cantidad de dinero proporcional a su PIB para funcionar (para permitir que las transacciones se realicen sin problemas).

Cuando, por algún motivo, la inflación aumenta o se acelera, es necesario que la oferta de dinero nominal aumente para preservar la cantidad real de dinero o liquidez de la economía. Para entender esto, se puede visualizar la liquidez monetaria necesaria del sistema como la cantidad de aceite lubricante que permite que una máquina funcione sin problemas, sin fricción. Así, la cantidad nominal de dinero es endógena y, dada la cantidad real de dinero necesaria, es la inflación la que requiere que su aumento se mantenga constante en términos reales. Si bien Keynes no dijo esto literalmente, mostró que la cantidad de dinero en una economía es endógena. Aquí en el Brasil, aprendí el carácter endógeno del dinero con Ignácio Rangel, que tuvo esa idea al observar la realidad brasileña desde principios de los años sesenta ${ }^{5}$. Entre los poskeynesianos, Basil Moore demostró teóricamente la endogeneidad de la moneda en $1979^{6}$.

3 De acuerdo con el Online Etymology Dictionary, la inflación en el sentido monetario de "aumento de los precios" (originalmente por un aumento en la cantidad de dinero en circulación) se registró por primera vez en 1838 en el inglés estadounidense. Véase [en línea] https://www.etymonline.com/word/inflation\#etymonline_v_6450.

4 En los Estados Unidos, la velocidad del agregado monetario M2 durante la Gran Depresión fue de 1,15 veces. Este valor aumentó a 1,67 en 1964 y a 1,89 en 1981. En 1997 alcanzó un máximo de 2,20 veces, para luego disminuir a 1,25 en 2018 y a 1,20 en 2020 (Banco de la Reserva Federal de St. Louis, 2020).

5 Véase Rangel (1963).

6 Véase Moore (1979). 
La teoría de la inflación inercial, en la forma en que se desarrolló en el Brasil -el país que tuvo la experiencia más larga y radical con este tipo de inflación-, lo demostró en forma definitiva en un artículo de 1984 que define ampliamente esa teoría y afirma esto en su propio título, "Fatores aceleradores, mantenedores e sancionadores da inflação" (factores que aceleran, mantienen y sancionan la inflación) (Bresser-Pereira y Nakano, 1984). El factor acelerador de la inflación puede ser un episodio de presión desde la oferta o la demanda, pero en la mayoría de los casos es el exceso de demanda en relación con la oferta. La indexación formal e informal de los precios es el factor inercial o de mantenimiento, que determina que la inflación sea resistente a las políticas habitualmente adoptadas para controlarla, y la indexación formal e informal de la economía es el factor sancionador, que mantiene constante la cantidad real de dinero en un ambiente en que la inflación reduce la cantidad nominal de dinero ${ }^{7}$. En cuanto al rechazo empírico del monetarismo, la flexibilización cuantitativa demostró definitivamente que el monetarismo no tiene sentido. Los bancos centrales de los países ricos compraron directamente del tesoro y del sector privado cerca de 15 billones de dólares sin aumentar la tasa de inflación.

Se puede decir que los países que emitieron dinero para financiar sus gastos relacionados con el COVID-19 tuvieron más libertad para gastar que los países que no pudieron hacerlo, como los de la zona del euro, que carecen de una moneda propia. Mientras en algunos países, como Australia, el Canadá y el Japón, se está gastando mucho (el 10,1\%, el 9,1\% y el 6,8\% del PIB, respectivamente), en otros, como Italia y España, se está gastando poco (el 1,2\% y el 2,7\% del PIB, respectivamente). Los países que gastan menos son precisamente los que cometieron el gran error de crear el euro y perdieron la autonomía de la política monetaria. Esto se vio claramente durante la crisis del euro (2010-2015) y aparentemente se repite en la crisis del COVID-19. Alemania, cuyos gastos ascienden al 6\% del PIB, constituye una excepción en este estudio, pero es sabido que la cuenta fiscal de ese país se administra con extremo rigor con miras a obtener enormes superávits en cuenta corriente y una industria competitiva. También sabemos cuán competente es su Canciller, Angela Merkel.

En el caso actual, además de aumentar la liquidez, esa compra no debe tener como objetivo reducir la deuda pública, como ocurrió con la flexibilización cuantitativa, sino financiar los gastos relacionados con el COVID-19 sin aumentar esa deuda. Según las proyecciones del Fondo Monetario Internacional (FMI, 2020c), a finales de este año la deuda pública del mundo rico aumentará de un $106 \%$ a un 122\% del PIB. En relación con el Brasil, se prevé un aumento del $78 \%$ al 95\% del PIB. De todos modos, los enormes gastos estatales necesarios para compensar la reducción de los ingresos de los Estados se traducirán en grandes déficits fiscales y, de no adoptarse el financiamiento monetario, en un aumento considerable de la deuda pública además de, pasada la crisis, un largo período de tiempo para pagar esa deuda.

El hecho de que el financiamiento monetario del gasto público no cause inflación a menos que haya un exceso de demanda en relación con la oferta no significa que los gobiernos puedan gastar a voluntad. Este límite no siempre está claro y no hay razón para correr riesgos innecesarios. Solo en circunstancias especiales, como la pandemia de COVID-19, es razonable utilizar esta forma de financiamiento. Ninguno de los tres países aquí analizados se está beneficiando de esa posibilidad: Francia porque no tiene una moneda propia y el Brasil y la Argentina porque tienen miedo de la inflación, que en este caso no se justifica.

\footnotetext{
7 Es por eso que, en su artículo básico sobre esta teoría, Bresser-Pereira y Nakano (1984) describieron la oferta de dinero como factor sancionador de la inflación.
} 


\section{Resultados económicos}

Veamos, finalmente, cuáles fueron los resultados de este gran esfuerzo fiscal realizado por los tres países de referencia. En el cuadro 1 se presentaron las tres medidas más importantes: el aumento del desempleo, el aumento de la pobreza y la reducción del PIB. El mayor aumento del desempleo se observa en el Brasil: la tasa de desocupación de la fuerza de trabajo creció 2,3 puntos porcentuales, en comparación con un incremento de 1,5 puntos porcentuales en la Argentina. En Francia se registra un dato sorprendente, pues no hubo un aumento, sino una disminución del desempleo. Al anunciar la reducción del 0,7\% del desempleo en el segundo trimestre del año, el Instituto Nacional de Estadística y Estudios Económicos (INSEE), responsable de las estadísticas del país, informó que el resultado era engañoso, porque muchos desempleados no fueron considerados durante los meses de reclusión debido a que no estaban buscando trabajo activamente (INSEE, 2020). El INSEE ignora, sin embargo, que en Francia hubo incentivos para que las empresas no despidieran a los trabajadores, mientras el Brasil y la Argentina fracasaron desde ese punto de vista. Aunque la ayuda de emergencia en el Brasil fue amplia y elevada, no hubo ninguna política pública que protegiera el empleo. Este mal desempeño en materia de empleo no fue exclusivo de esos dos países latinoamericanos. Según un estudio de la Comisión Económica para América Latina y el Caribe publicado el 2 de julio (CEPAL, 2020), en los próximos seis meses cerrarán más de 2,7 millones de empresas y se perderán más de 8,5 millones de puestos de trabajo formales en América Latina y el Caribe a causa de la pandemia de COVID-19. En el informe se evalúan las repercusiones y los retos enfrentados por las empresas durante la pandemia y se informa que más de un tercio del empleo formal y una cuarta parte del PIB de la región se generan en sectores muy afectados por la crisis actual. Asimismo, se indica que 2,6 millones de las empresas que deberán cerrar debido a la crisis son microempresas, 1,4 millones de las cuales pertenecen al sector del comercio y 290.000 al del turismo, segmentos especialmente afectados por las medidas restrictivas adoptadas por los gobiernos para impedir la propagación del nuevo coronavirus.

El mejor desempeño del Brasil fue en relación con la pobreza, que disminuyó un 0,9\% en comparación con un 0\% en Francia y un aumento del 11,5\% en la Argentina. La disminución de la pobreza en el Brasil está directamente relacionada con la ayuda de emergencia, que fue generosa y de gran magnitud. Mientras ese beneficio fue de 600 reales, la prestación del programa de transferencias condicionadas Bolsa Família puede llegar a un máximo de 205 reales cuando en la familia hay cinco beneficiarios. Asimismo, aunque se preveían 50 millones de beneficiarios, se llegó en realidad a 66,9 millones de personas, mientras que Bolsa Família atiende a 14,2 millones de personas.

Por último, si bien se observa una acentuada disminución de los ingresos en los tres países, el peor desempeño corresponde a Francia, donde la reducción del PIB estimada para este año asciende al 12,5\%, frente a una reducción del 9,1\% en el Brasil y del 9,9\% en la Argentina. Aunque esta mayor reducción en Francia es comprensible, porque fue el país que menos gastó para neutralizar los efectos negativos de la pandemia, el dato contradice el hecho de que en el segundo trimestre del año no se registrara un aumento, sino una pequeña disminución del desempleo. La reducción del 9,1\% del PIB brasileño prevista para 2020 es compatible con el marcado aumento del desempleo.

\section{Conclusión}

En resumen, aunque el Brasil gastó más que Francia y la Argentina en relación con el PIB, sus resultados en cuanto al número de muertes causadas por el COVID-19 fueron mucho peores que los de esos dos países. El peor resultado de Francia con respecto a la Argentina derivó de la demora inicial del Gobierno en actuar, mientras el peor resultado del Brasil se debió a que, más que una política de lucha 
contra el virus, el Gobierno federal aplicó una antipolítica, que fue compensada solo parcialmente por las decisiones del Congreso Nacional y los gobernadores y por la existencia, desde la transición democrática, de un sistema de salud universal. No obstante, el Brasil fue el país que más gastó con respecto al COVID-19 debido, principalmente, a la amplia y generosa ayuda de emergencia adoptada por el Congreso Nacional. Esto fue lo que permitió obtener un resultado mejor que el de la Argentina en términos de aumento de la pobreza, e incluso que esta disminuyera levemente. La reducción del PIB, sin embargo, fue solo ligeramente menor en el Brasil que en los otros dos países examinados.

\section{Bibliografía}

Banco de la Reserva Federal de St. Louis (2020), "Velocity of M2 Money Stock (M2V)" [en línea] https://fred. stlouisfed.org/series/M2V.

Bresser-Pereira, L. e Y. Nakano (1984), "Fatores aceleradores, mantenedores e sancionadores da inflação", Revista de Economia Política, vol. 4, № 1.

CEPAL (Comisión Económica para América Latina y el Caribe) (2020), "Sectores y empresas frente al COVID-19: emergencia y reactivación", Informe Especial COVID-19, № 4, 2 de julio [en línea] https:// repositorio.cepal.org/bitstream/handle/11362/45734/4/S2000438_es.pdf.

FMI (Fondo Monetario Internacional) (2020a), "Actualización de las perspectivas de la economía mundial", junio [en línea] https://www.imf.org/es/Publications/WEO/Issues/2020/06/24/WEOUpdateJune2020.

(2020b), "Policy responses to Covid-19" [en línea] https://www.imf.org/en/Topics/imf-and-covid19/ Policy-Responses-to-COVID-19.

(2020c), "Una crisis como ninguna otra, una recuperación incierta", Actualización de las Perspectivas de la Economía Mundial, Washington, D.C., junio.

INDEC (Instituto Nacional de Estadística y Censos) (2020), "Mercado de trabajo: tasas e indicadores socioeconómicos (EPH)", Trabajo e Ingresos, vol. 4, № 3, junio.

Institución Fiscal Independiente (2020), Relatório de Acompanhamento Fiscal, № 43, 17 de agosto [en línea] https:// www2.senado.leg.br/bdsf/bitstream/handle/id/575506/RAF43_AGO2020.pdf.

INSEE (Instituto Nacional de Estadística y Estudios Económicos) (2020), "In Q2 2020, the labour market under the influence of containment", 13 de agosto [en línea] https://www.insee.fr/en/statistiques/4642442\#consulter.

Moore, B. (1979), "The endogenous money stock", Journal of Post Keynesian Economics, vol. 2, № 1.

Natanson, J. (2020), "Argentina, el virus y el presidente", Nueva Sociedad, № 287.

OPC (Oficina de Presupuesto del Congreso) (2020), "Análisis de la ejecución presupuestaria de la Administración Nacional, junio 2020” [en línea] https://www.opc.gob.ar/informes/analisis-de-la-ejecucion-presupuestariade-la-administracion-nacional-junio-2020/.

Rangel, I. (1963), A inflação brasileira, Río de Janeiro, Tempo Brasileiro.

Ruprecht, T. (2020), "Entrevista: por que o número de mortes por coronavírus está subestimado", Veja Saúde, 1 de mayo [en línea] https://saude.abril.com.br/medicina/entrevista-por-que-o-numero-de-mortes-porcoronavirus-esta-subestimado/.

Sousa Pinto, A. (2020), "Taxa de positivo em testes indica que epidemia está subestimada no Brasil, diz OMS", Folha de S. Paulo, 23 de junio [en línea] https://www1.folha.uol.com.br/equilibrioesaude/2020/06/ taxa-de-positivo-em-testes-indica-que-epidemia-esta-subestimada-no-brasil-diz-oms.shtml.

The Economist (2020), "Free money: when government spending knows no limits", 25 de julio [en línea] https://www.economist.com/weeklyedition/2020-07-25.

UOL (2020), “'Poderíamos ter tido um terço das mortes', diz professor da USP sobre covid", 29 de mayo [en línea] https://noticias.uol.com.br/saude/ultimas-noticias/redacao/2020/05/29/entrevista-paulo-lotufoprofessor-de-epidemiologia-da-usp.htm?cmpid=copiaecola\&cmpid=copiaecola. 